\title{
Electrospun Adsorptive Nanofibrous Membranes from Ion Exchange Polymers to Snare Textile Dyes from Wastewater \\ DOI:
}

10.1002/admt.202000955

\section{Document Version}

Accepted author manuscript

Link to publication record in Manchester Research Explorer

\section{Citation for published version (APA):}

Cseri, L., Topuz, F., Abdulhamid, M. A., Alammar, A., Budd, P. M., \& Szekely, G. (2021). Electrospun Adsorptive Nanofibrous Membranes from Ion Exchange Polymers to Snare Textile Dyes from Wastewater. Advanced Materials Technologies, pp, [2000955]. https://doi.org/10.1002/admt.202000955

\section{Published in:}

Advanced Materials Technologies

\section{Citing this paper}

Please note that where the full-text provided on Manchester Research Explorer is the Author Accepted Manuscript or Proof version this may differ from the final Published version. If citing, it is advised that you check and use the publisher's definitive version.

\section{General rights}

Copyright and moral rights for the publications made accessible in the Research Explorer are retained by the authors and/or other copyright owners and it is a condition of accessing publications that users recognise and abide by the legal requirements associated with these rights.

\section{Takedown policy}

If you believe that this document breaches copyright please refer to the University of Manchester's Takedown Procedures [http://man.ac.uk/04Y6Bo] or contact uml.scholarlycommunications@manchester.ac.uk providing relevant details, so we can investigate your claim.

\section{OPEN ACCESS}


Electrospun adsorptive nanofibrous membranes from ion exchange polymers to snare textile dyes from wastewater https://doi.org/10.1002/admt.202000955

Levente Cseri, Fuat Topuz, Mahmoud A. Abdulhamid, Abdulaziz Alammar, Peter M. Budd, Gyorgy Szekely*

L. Cseri, A. Alammar, Prof. G. Szekely

Department of Chemical Engineering, University of Manchester, The Mill, Sackville Street, Manchester M1 3BB, United Kingdom

Dr. F. Topuz, Dr. M. A. Abdulhamid, Prof. G. Szekely

Advanced Membranes \& Porous Materials Center, Physical Science Engineering Division (PSE), King Abdullah University of Science and Technology (KAUST), Thuwal 23955-6900, Saudi Arabia

E-mail: gyorgy.szekely@kaust.edu.sa, Web: www.szekelygroup.com, Phone: +966128082769

Prof. P. M. Budd

Department of Chemistry, University of Manchester, Oxford Road, Manchester, M13 9PL, United Kingdom

Keywords: water treatment; electrospinning; ion exchange; polyelectrolytes; polyimides

Increasing discharges of industrial wastewater, along with ever-stricter regulations for the protection of natural water sources, have amplified the demand for highly efficient water treatment technologies. Here, electrospun nanofibrous polyimides enhanced with ion exchange properties are proposed as adsorptive membranes for the treatment of dye-loaded textile wastewater. With the careful selection of monomers, carboxyl-functionalized porous polyimides are synthesized in a single step and then further decorated with strong cation and anion exchange side groups. Nuclear magnetic resonance (NMR) spectroscopy and thermal gravimetric analysis (TGA) are used to investigate the alkylation degree and total exchange capacity of the polymers. The electrospinning conditions are optimized to produce highly flexible membrane mats with a uniform nanofibrous structure. A series of dye sorption experiments on the nanofibrous membranes reveals the adsorption kinetics and the effects of the polyimide backbone, the charged side groups, and the hydrophilicity. A recycling study is conducted to confirm the stability of the adsorbent membranes. The results suggest that nanofibrous polyimide membranes enhanced with ion exchange properties are promising 


\section{WILEY-VCH}

candidates for the treatment of dye-laden wastewater. Owing to their facile syntheses and unique properties, these membranes show promising potential in environmental applications.

\section{Introduction}

Freshwater scarcity is becoming one of the great challenges of the 21 st century. Driven by increasing population and industrialization, global water withdrawal has been increasing sharply over the past 100 years by approximately five fold. ${ }^{[1]}$ The UN forecasts another $55 \%$ increase in the first half of this century, mostly driven by the industrial and municipal sectors. ${ }^{[2]}$ Climate change and industrial pollution put traditional freshwater sources under severe pressure. As a consequence, ever-stricter environmental regulations are being legislated to minimize the discharge of industrial pollutants to protect freshwater resources. ${ }^{[3]}$ One of the largest volumes and the most problematic types of wastewater is the effluent from the textile industry, whose water consumption can reach as high as 216 million $\mathrm{m}^{3}$ day $^{-1} \cdot{ }^{[4]}$ Millions of metric tons of synthetic dyes are produced globally every year, with the main demand coming from the textile industry. ${ }^{[5]}$ Exact numbers have not been established, but they surely exceed the commonly cited - even in 2020 - numbers of "100,000 dyes and $7.5 \times 10^{5}$ tons" as those appear as early as $1981 .{ }^{[6]}$ Due to the incomplete binding of the dyes to the fabric material, it is estimated that a significant portion, around 5-20\% of the total amount of dyes used remain in the effluent water. ${ }^{[7]}$

The treatment of this dye-laden wastewater is essential for multiple reasons. Some dyes are directly and acutely toxicity to the natural water ecosystem, but even those dyes that are not toxic absorb sunlight and thus decrease photosynthesis. ${ }^{[8]}$ This effect, combined with the high oxygen demand from the decomposition of dyes, deprives natural waters of dissolved oxygen. Apart from environmental pollution, many dyes are toxic to humans and cause allergic reactions or even potential mutagenic or carcinogenic effects. ${ }^{[8]}$

Biological and chemical treatment, membrane processes, and adsorption or a combination of these processes are used for the treatment of textile wastewater. Biological treatment is limited 


\section{WILEY-VCH}

in scope because it usually suffers from low color removal and because many dyes have antimicrobial properties. ${ }^{[9]}$ Chemical treatment is robust and efficient at removing dyes, but expensive reagents and secondary pollution remain obstacles. ${ }^{[10]}$ Membrane processes and adsorption are low-cost but highly efficient processes for the removal or even for the recovery of dyes. Conventional thin-film composite or integrally skinned asymmetric nanofiltration membranes have been shown to have good rejections rates for many dyes, but fouling can severely compromise their performance. ${ }^{[11]}$ A plethora of materials have been considered as adsorbent materials for water treatment, including zeolites, ion exchange resins, waste materials, and by-products. ${ }^{[12]}$ Activated carbon is currently the state-of-the-art adsorbent for water treatment due to its high capacity and ready availability. However, activated carbon adsorption beds often suffer from high pressure drops and complicated regenerability. ${ }^{[13]}$ In addition, the adsorption performance of activated carbon toward anionic dyes is not sufficient without chemical modifications, which compromise its versatility and cost attractiveness. ${ }^{[14]}$

On the other hand, electrospinning technology has attracted attention for the production of adsorptive membranes due to the excellent control it provides over structural properties that can be tailored for specific applications. Electrospinning can produce ultrafine fibers that are randomly or directionally assembled into mats ranging in size from several centimeters up to meters. The process uses viscous polymer solutions, which overcome their surface tension through electrostatic traction to produce a continuous jet. The jet is then drawn out into a highly porous $(>80 \%)$ nanofibrous mat. Electrospinning can also formulate nanomaterials with an extremely large surface-to-volume ratio for macroscopic assemblies. ${ }^{[15]}$ Owing to their high surface-to-volume ratio, high pore volume, low density and increased flexibility compared with their film counterparts, electrospun nanofibrous membranes are thus effective adsorbents that can scavenge pollutants. However, most polymers used in the preparation of electrospun membranes, such as cellulose acetate, poly(vinyl alcohol), poly(vinylidene fluoride) or poly(acrylic acid), either have poor adsorptive properties as stand-alone materials due to the 


\section{WILEY-VCH}

lack of high-affinity binding sites or inadequate stability in water. They are therefore mostly used in composites with other materials, such as cyclodextrin ${ }^{[16,17]}$ or polydopamine ${ }^{[18,19]}$, that provide binding sites for adsorption. Recently, Chen et al. tested multifunctional cellulose acetate nanofibers for the adsorption of ionic dyes. ${ }^{[20]}$ Good adsorption capacities and reusability were reported at high $\mathrm{pH}$, and the electrostatic attraction and hydrogen bonding introduced by the polydopamine coating on the adsorbent were identified as the main driving forces of the adsorption process.

Similarly, electrostatic interactions have been cited as the rationale for the use of ion exchange resins in adsorption processes. ${ }^{[21]}$ Recent research has focused on the use of bio-derived materials in these resins after crosslinking and ionic functionalization. ${ }^{[2,23]}$ However, some of these materials, such as lignocellulosic adsorbents, exhibited poor binding capacities while crosslinking and covalent modification may compromise their biodegradability, the main advantage of these adsorbents. ${ }^{[21]}$

Another emerging group of high-performance, solution-processable polymers is polyimides with applications in numerous separation fields, including gas separation, nanofiltration, and liquid-liquid phase separation. ${ }^{[24-26]}$ Functionalized polyimides attracted attention in the last decade for selective separations, which resulted from their functionalized side chains, such as, $-\mathrm{CH}_{3},-\mathrm{COOH}$, and -OH groups. ${ }^{[27-29]}$ The polyimides demonstrated good chemical resistance, thermal stability, and mechanical strength originating from the intrinsic behavior of the imide structure and the presence of rigid aromatic and aliphatic moieties. ${ }^{[30,31]}$ Moreover, functionalized polyimides provide a great platform for different types of modifications and crosslinking. ${ }^{[32]}$ Polyimide-based porous organic frameworks ${ }^{[33]}$ and more hydrophilic polyimide-silica composites ${ }^{[34]}$ have recently been proposed for the removal of dyes and heavy metal ions from their aqueous solutions. While the results were promising, the formulation of these crosslinked materials is problematic in contrast to that of linear polyimides, which can be formulated into larger-scale adsorbent materials - via electrospinning for example - owing to 


\section{WILEY-VCH}

their solubility in certain polar aprotic solvents. With the careful selection of the monomers, highly porous polyimides can be obtained. ${ }^{[35]}$ These polymers can be turned into adsorbent materials with unique properties after functionalization and formulation.

In this work, the syntheses of three anionic and three cationic polyelectrolytes are reported from carboxyl-functionalized porous polyimides in a single step. The ionic sites along with the carboxylic groups are expected to give rise to strong interactions between the polymer and ionic organic compounds, such as dyes. The ionic polymers are formulated into nanofibrous membranes via electrospinning. Adsorption tests with eight dyes are performed alongside the study of adsorption kinetics, mechanics, and recyclability. The chemistry and morphology of the polymers and nanofibrous membranes are thoroughly characterized to establish connections between the properties and performance. Figure 1 provides an illustrative overview of this work, including the general structure of the synthesized polymers, a schematic view of the electrospinning process, and the range of dyes used for the adsorption experiments.

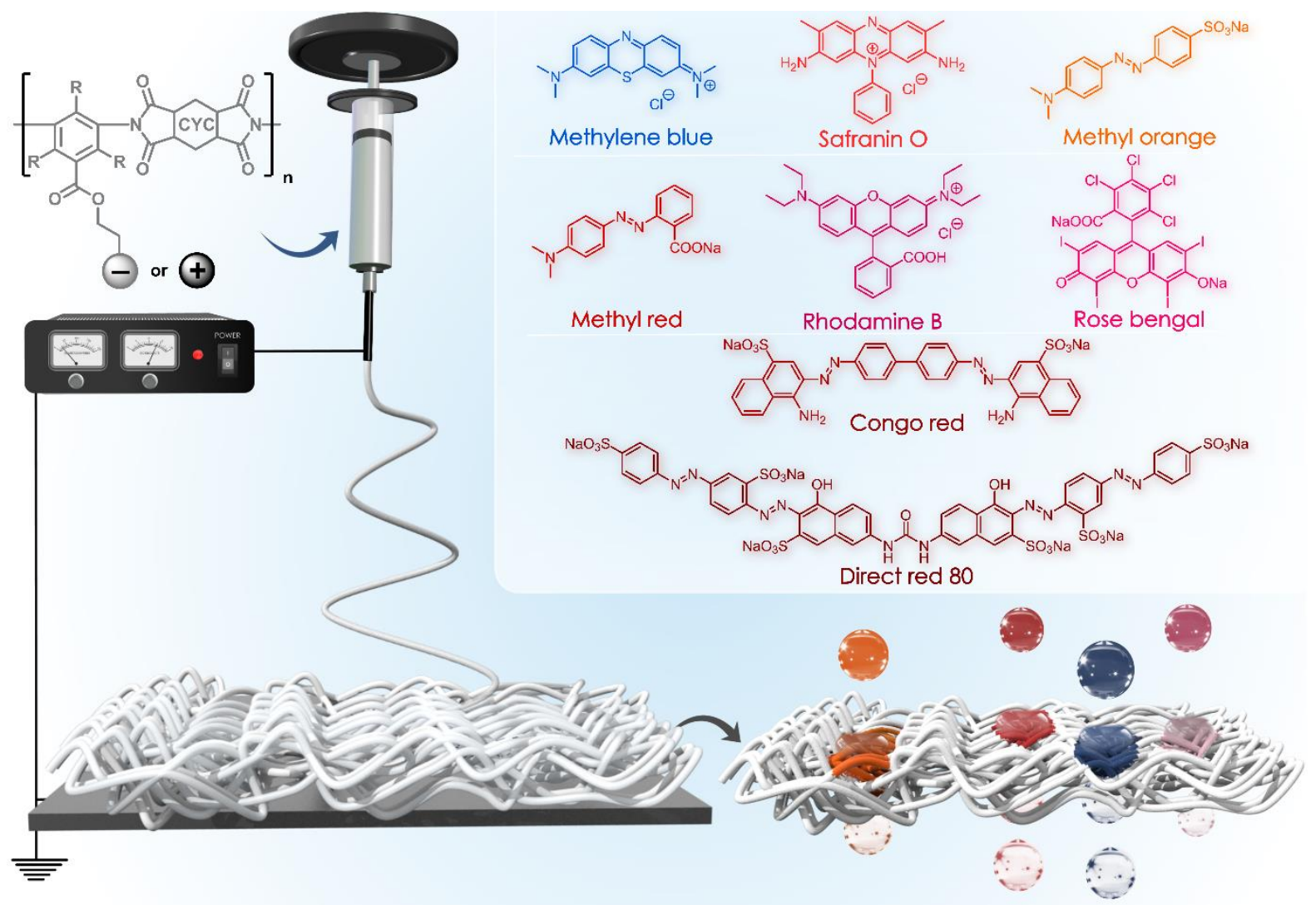

Figure 1. Fabrication of nanofibrous membranes from polyelectrolytes via electrospinning with the structure of dyes screened in the adsorption experiments shown in the inset. 


\section{WILEY-VCH}

\section{Results and Discussion}

The three carboxyl-functionalized polyimides, namely BCDA-DABA (P1), 6FDA-DABA (P2), and 6FDA-TrMCA (P3), were prepared via a one-step, high-temperature polycondensation reaction by reacting equimolar amounts of the dianhydride and the diamine in $m$-cresol and in the presence of isoquinoline at $200{ }^{\circ} \mathrm{C}$ (Figure 2). The molecular structures of the obtained carboxyl-functionalized polyimides were confirmed by ${ }^{1} \mathrm{H}$ and ${ }^{13} \mathrm{C} \mathrm{NMR}$, in addition to Fouriertransform IR spectroscopy (FTIR). Gel permeation chromatography (GPC) indicated that all three polymers high molecular weight with $M_{\mathrm{n}}$ in the range of $44-114 \mathrm{~kg} \mathrm{~mol}^{-1}$. The carboxyl groups can be transformed into ester moieties to introduce various side groups to the polymer. Based on the solubility of the polyimides and preliminary experiments, O-alkylation was selected as a suitable strategy for straightforward ester formation. As reagents, 1,3propanesultone and chlorocholine chloride (CCC) were selected to introduce cation and anion exchange functionalities, respectively. Compared with the traditional method of introducing ion exchange groups into various polymers, namely sulfonation using concentrated sulfuric acid or oleum, chloromethylation using chloromethyl methyl ether or alkylation using methyl iodide, O-alkylation provides a more benign approach without the need for dangerous reagents. Moreover, it allows the introduction of cationic or anionic groups in the same position of the polymeric chain, which simplifies the comparison of the two derivatives in terms of structureproperty relationships. Therefore, three cation exchange polyimides, CEP1-CEP3, and three anion exchange polyimides, AEP1-AEP3, were synthesized in O-alkylation reactions from the parent polymers in $\mathrm{N}, \mathrm{N}$-dimethylformamide (DMF) at $60{ }^{\circ} \mathrm{C}$ in the presence of $\mathrm{K}_{2} \mathrm{CO}_{3}$ base. 


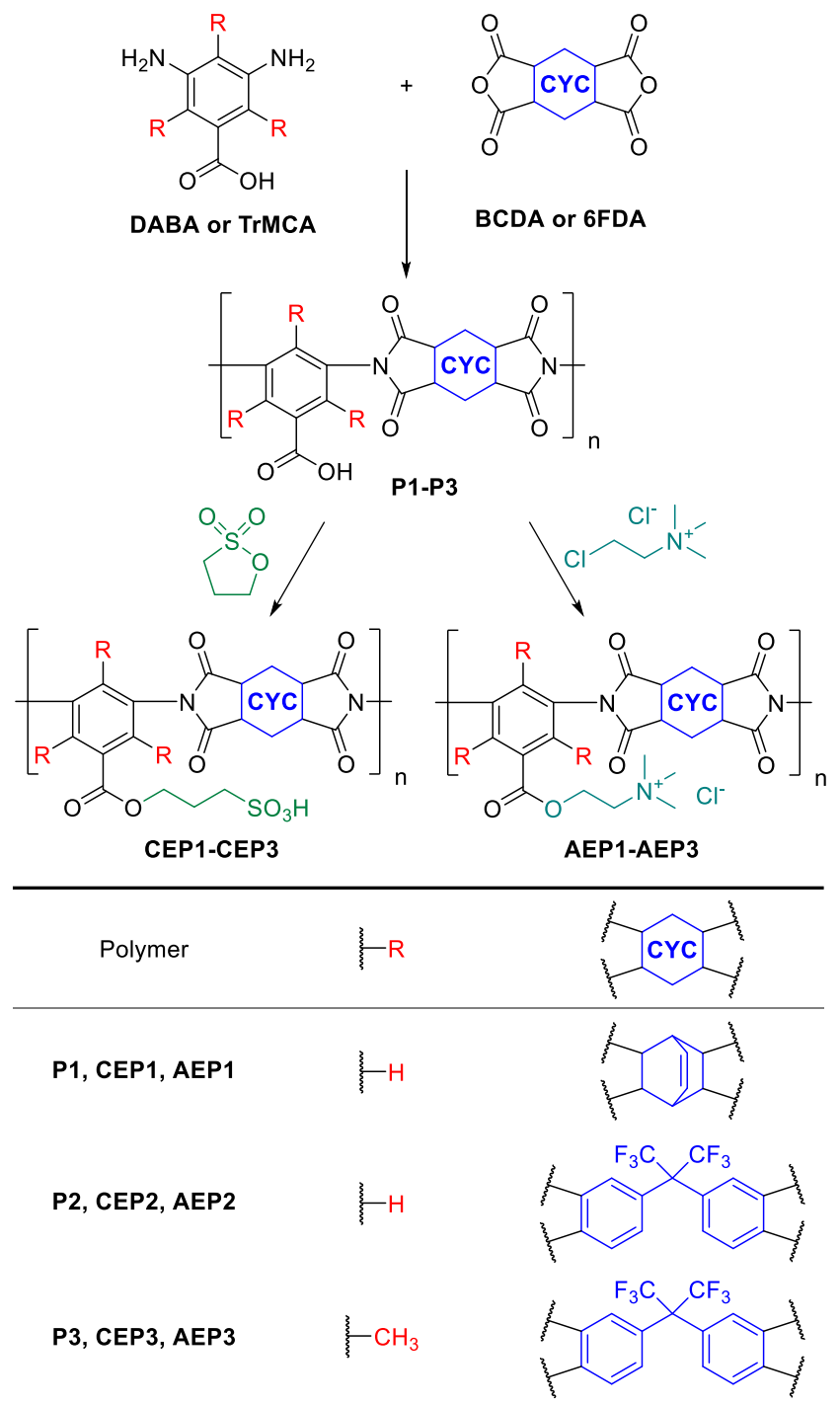

Figure 2. Synthesis of polyimides bearing strong cation exchange and anion exchange functionalities in their side groups.

The successful modification of the polymers was confirmed by NMR and FTIR. Figure 3 summarizes the results from the different techniques for the modification of $\mathbf{P 1}$. The same conclusions can be drawn from these analytical techniques in the cases of the other polymers whose spectra can be found in the Supporting Information. In the ${ }^{1} \mathrm{H}$ NMR spectrum of the parent polymer, P1, five broad peaks can be observed corresponding to the five different chemical environments of the polymer backbone (Figure 3a). Three additional peaks at 2.03, 2.63 and 4.39 ppm can be observed in the spectrum of CEP1 in agreement with expectations for the trimethylenesulfonic acid side group. These peaks are also quite broad, which indicates that they are part of a polymeric structure. Nevertheless, deconvolution of the peaks reveals a 


\section{WILEY-VCH}

triplet-quintet-triplet pattern typical of a trimethylene moiety. The identical integrals of these three peaks confirm that they belong to the same number of hydrogen atoms. The relative integrals of the methylene peaks compared with those of the peaks of the polymer backbone can be used to calculate the alkylation degree of the carboxylic acid groups. In the case of CEP1, this value is 0.47 side group per repeating unit. CEP2 and CEP3 exhibit higher alkylation degrees with respective values of 0.81 and 0.87. In the case of CEP1, the splitting of the signal corresponding to the aromatic hydrogens in the ortho position relative to the carboxylic groups also indicates the successful partial alkylation of these groups. The relative areas of these split peaks are 0.47 to 0.53 , in good agreement with the calculated alkylation degree. There are also three new peaks in the ${ }^{1} \mathrm{H}$ NMR spectrum of AEP1 corresponding to the choline ester side group. The relative areas of these peaks are 2 to 2 to 9 in line with expectations. The alkylation degree is 0.19 side group per repeating unit, which is lower than that for CEP1. This difference reflects the different reactivity of 1,3-propanesultone and $\mathrm{CCC}$ as alkylating reagents because alkylsulfonate ions are better leaving groups than chloride ions. ${ }^{[36]}$ The ${ }^{13} \mathrm{C}$ NMR spectra of the ion exchange polymers are also consistent with the presence of side groups (Figure 3b). In the spectrum of CEP1 aliphatic, carbon signals at 64.7, 47.9, and 24.7 ppm can be observed; these signals belong to the trimethylenesulfonic acid group. Splitting of the carboxyl and some aromatic signals indicates the changed chemical environment due to the alkylation, in agreement with the ${ }^{1} \mathrm{H}$ results. The aliphatic carbon signals in AEP1 are less pronounced due to the lower alkylation degree. The presence of ${ }^{13} \mathrm{C}-{ }^{14} \mathrm{~N} J$-coupling causes further broadening and decreased peak height. Nevertheless, the spectrum is in agreement with the expected ester structure with choline ester signals at 63.7, 59.3, and 52.9 ppm. The FTIR spectra of P1, CEP1, and AEP1 show little variation, suggesting that most of the observed peaks originate from the polymeric backbone (Figure 3c). Nonetheless, extra peaks in the FTIR spectrum of CEP1 at around 1034 and $1140 \mathrm{~cm}^{-1}$ may indicate the presence of aliphatic $\mathrm{C}-\mathrm{C}$ stretching and $\mathrm{O}=\mathrm{S}=\mathrm{O}$ 


\section{WILEY-VCH}

symmetric stretching vibrations, respectively. The increased intensity of the peak at around 767 $\mathrm{cm}^{-1}$ in the spectrum of AEP1 might originate from aliphatic $\mathrm{N}-\mathrm{C}$ stretching vibrations. GPC analysis suggested some degradation of the main polymer chains as the molecular weight values of the modified polymers were well below those of pristine polyimides with $M_{\mathrm{n}}$ in the range of $13-41 \mathrm{~kg} \mathrm{~mol}^{-1}$. The decreased molecular weight was also supported by the dramatically improved solubility of the polymers in polar aprotic solvents. This change in molecular weight may be attributed to the alkaline hydrolysis of phthalimide moieties in the presence of trace amounts of water during the O-alkylation reaction. ${ }^{[37]}$ This hydrolysis would produce a more stable amide intermediate prior to chain scission. However, the characteristic signal of the amide $>\mathrm{NH}$ group is not observed the ${ }^{1} \mathrm{H}$ NMR spectra of the modified polymers except in the cases of CEP3 and AEP3. Even there, the signal strength is too low to support imide-to-amide hydrolysis as the main cause for the decreased molecular weight. 

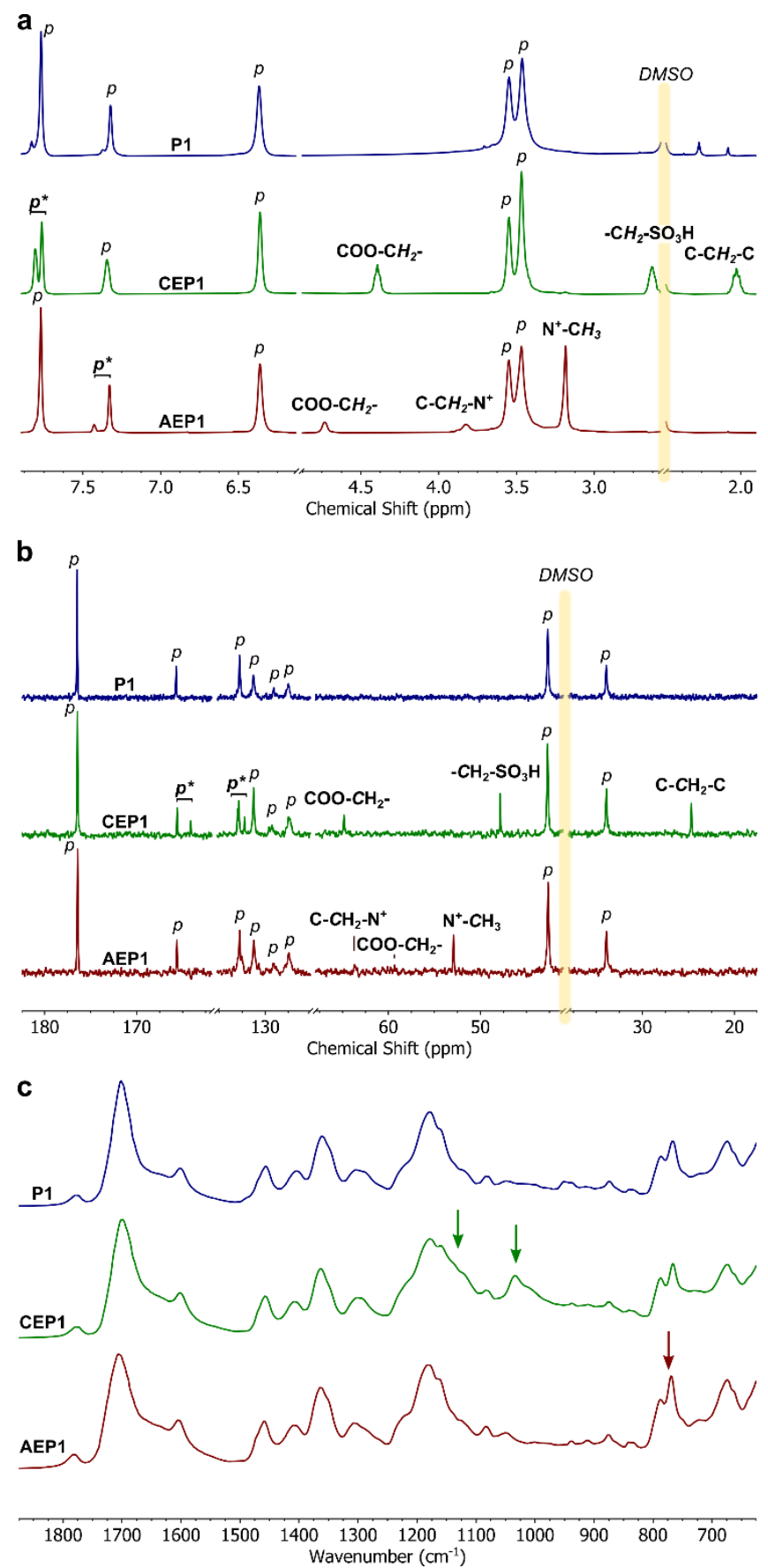

Figure 3. a) ${ }^{1} \mathrm{H}$ NMR; b) ${ }^{13} \mathrm{C}$ NMR; and c) FTIR spectra of P1, CEP1, and AEP1 showing the emergence of aliphatic signals in the ionic polymers that confirm the successful attachment of the side groups. In the NMR spectra, the signals of the polymeric backbone are labeled as $p$ and those that are split or shifted due to the modification are labeled as $\boldsymbol{p}^{*}$.

The thermal properties and degradation of the polymers were studied using thermal gravimetric analysis (TGA) and differential scanning calorimetry (DSC) as shown in Figure 4. The TGA analysis confirmed the excellent heat resistance of the parent polyimides (P1-P3). No significant degradation of these polymers occurred below $375{ }^{\circ} \mathrm{C}$. The degradation of the 


\section{WILEY-VCH}

carboxyl-functionalized parent polyimides (P1-P3) started with decarboxylation and the thermal degradation of the $-\mathrm{COOH}$ functionality at around $375^{\circ} \mathrm{C} .{ }^{[28]}$ The mostly aliphatic $\mathbf{P 1}$ backbone degraded at similar temperatures, between $375-450{ }^{\circ} \mathrm{C}$, in contrast with $475-550{ }^{\circ} \mathrm{C}$ in the cases of the more stable, mostly aromatic P2 and P3. The ion exchange polymers showed another weight loss step between $200-300{ }^{\circ} \mathrm{C}$, which is consistent with the degradation of the aliphatic side groups. ${ }^{[38]}$ If one assumes complete degradation of the side groups, an intact polymer backbone at $375^{\circ} \mathrm{C}$ and an approximately identical amount of trace impurities such as solvent or moisture, which are desorbed below $375^{\circ} \mathrm{C}$, the alkylation degree can be estimated. These estimated values correlate well with the values obtained from the NMR spectroscopy with an average deviation of 0.04 side group per repeating unit. This result also supports the probability of side group degradation below $375{ }^{\circ} \mathrm{C}$. Further degradation steps of the ion exchange polymers follow the same pattern as those of the parent polymer. The DSC analysis found no thermal glass transition temperature $\left(T_{\mathrm{g}}\right)$ for pristine polymers $(\mathbf{P 1}-\mathbf{P 3})$ up to $350{ }^{\circ} \mathrm{C}$, in agreement with previous reports in the literature for these types of polyimides. ${ }^{[28]}$ Similarly, for the modified polymers, no $T_{\mathrm{g}}$ was obtained below the decomposition temperature of the polymer backbone, indicating the rigidity of these polymers. ${ }^{[27,28,39]}$ 

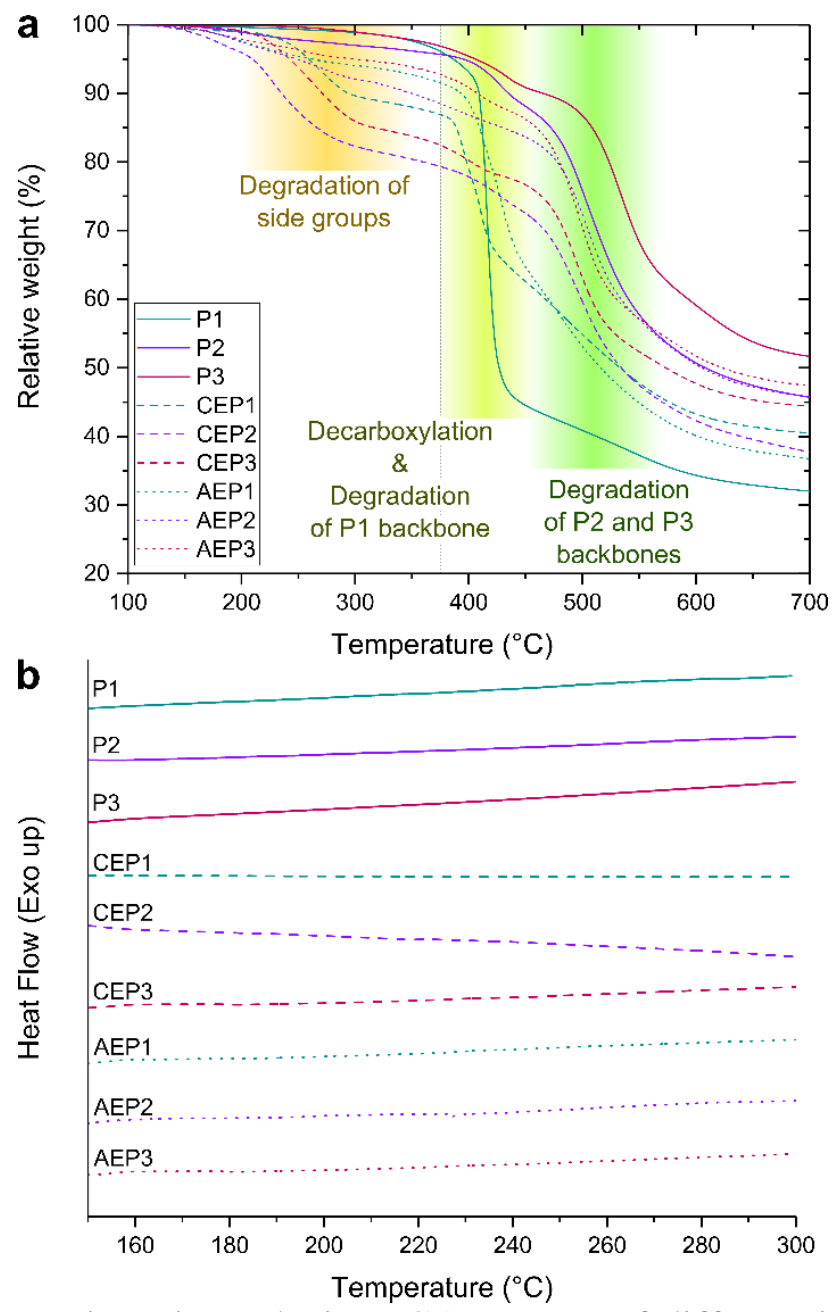

Figure 4. a) Thermal gravimetric analysis (TGA) curves of different ion exchange polymers (CEP1-CEP3 and AEP1-AEP3) and their parent polymers (P1-P3) showing different steps of degradation; b) differential scanning calorimetry (DSC) curves of the different polymers showing no endothermic or exothermic phase transition in the temperature range $150-300{ }^{\circ} \mathrm{C}$.

The introduction of ionic side groups on the carboxylic groups of P1-P3 was confirmed by the chemical (NMR) and thermal analysis (TGA). The alkylation degrees calculated from the two methods were in reasonably good agreement. The alkylation degree obtained from NMR is more reliable among the two measures, due to the fewer assumptions made during its calculation. These values can be used to calculate the theoretical ion exchange capacity or the total exchange capacity (TEC) of the polymers. As shown in Figure 5a, TEC values were in the range of $1.12-1.23 \mathrm{mmol} \mathrm{g}^{-1}$ for the cation exchange polymers and $0.47-0.86 \mathrm{mmol} \mathrm{g}^{-1}$ for the anion exchange polymers. The higher TEC of CEP1-CEP3 compared with that of AEP1- 


\section{WILEY-VCH}

AEP3 was a direct result of the lower alkylation degree, as discussed earlier. However, all values are well within the range reported for commercial ion exchange polymers. ${ }^{[40,41]}$

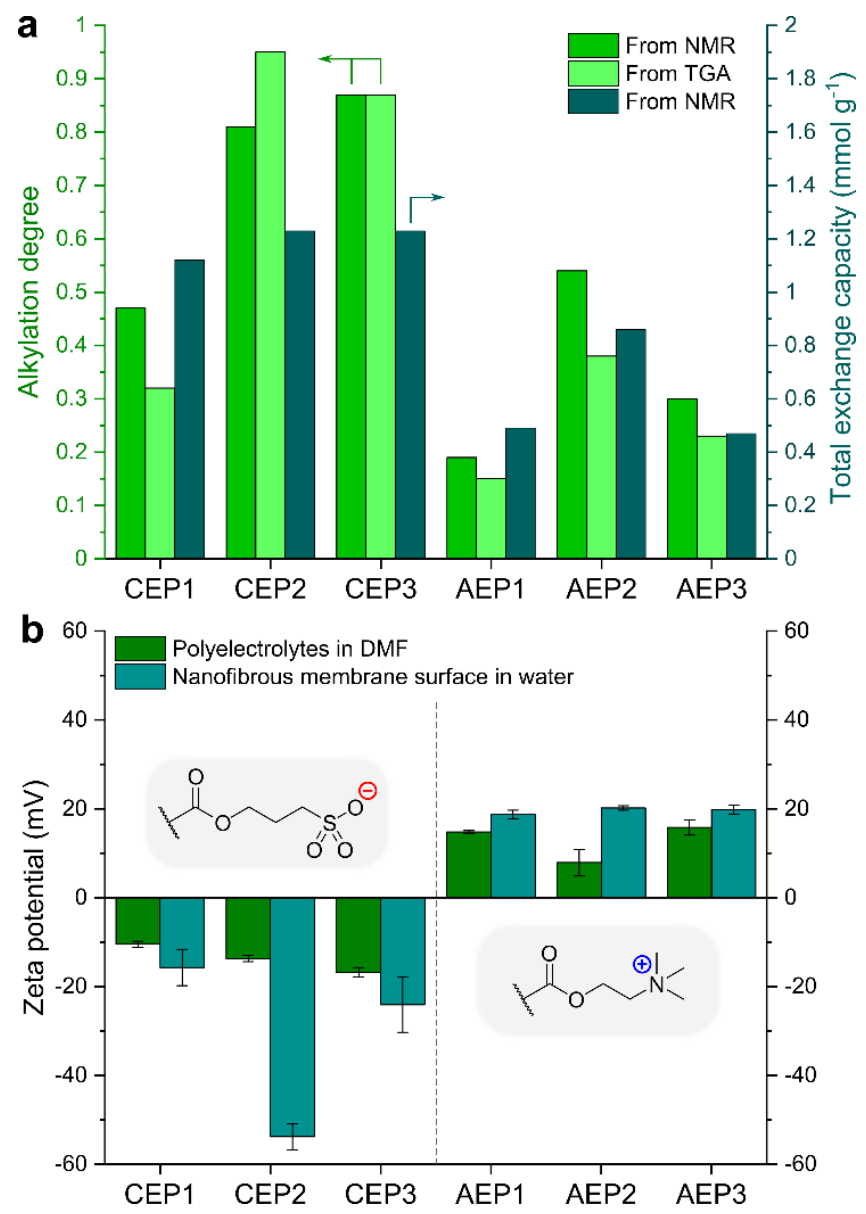

Figure 5. a) Alkylation degree of the different ion exchange polymers as obtained by NMR and TGA and total exchange capacity (TEC) calculated from the NMR results; b) zeta potentials of the ion exchange polymers dissolved in DMF and the nanofibrous membrane surfaces in water.

Since polyelectrolytes are polymers with ionic groups on their repeating segments, they become charged via the dissociation of small counterions from a charged macro polyion in a polar medium. Owing to their charged structure, under an electrical field they behave like particles. Their mobility and zeta potential can therefore be measured as an intrinsic characteristic of the polyelectrolyte. To prevent variations in the zeta potential, these experiments were carried out at a fixed concentration of $2.5 \mathrm{mg} \mathrm{mL}^{-1}$ in DMF. In agreement with the ion exchange nature of the side groups introduced via the O-alkylation, the polymers gave either negative (CEP1CEP3) or positive (AEP1-AEP3) zeta potential values (Figure 5b). The absolute values of the zeta potential were in the range of $11.0-16.5 \mathrm{mV}$ for all polyelectrolytes. After the 


\section{WILEY-VCH}

electrospinning, zeta potential values were also measured for the fibers immersed in deionized water. The fibers show a similar trend to their respective polymer solutions with different values; i.e., negative zeta potential for anionic polymers and positive zeta potential for cationic polymers. This also means that the surface of the fibers is decorated by the charged group in the repeating segments of the polymers.

Figure S31 displays a typical mat obtained by the electrospinning of AEP2. The mat was highly flexible and could be folded and even twisted without development of any cracks. This can be attributed to secondary interactions between the polymer chains that are strong enough to maintain fiber flexibility under deformation.

At lower concentrations of the respective polymer solutions, the electrospinning process yielded beads and beaded fibers (Figure S32). At such concentrations, the jet became unstable and broke into drops. Continuous electrospinning of the polymer solutions could therefore not be sustained. On the other hand, as the polymer concentration was increased, electrospun fibers could be produced as a result of the formation of a continuous jet. Figure $\mathbf{6}$ shows the scanning electron micrographs of the fibers spun from DMF solutions at different polymer concentrations at the applied voltage of $15 \mathrm{kV}$. Owing to the differences in the molecular weights of the polymers and the conductivities of the polymer solutions, nanofibers could be obtained at different concentrations depending on the polymer used as shown in Table S2. All spun fibers were formed with mean diameters in the nanoscale range, confirming the formation of nanofibers. The nanofibers spun from CEP1, CEP2, AEP2, and AEP3 revealed very uniform fiber structures with narrow standard deviations. The mean diameters of the nanofibers were found to be $380 \pm 125 \mathrm{~nm}, 450 \pm 75 \mathrm{~nm}, 540 \pm 65 \mathrm{~nm}$, and $320 \pm 45 \mathrm{~nm}$ for CEP1, CEP2, AEP2, and AEP3, respectively. On the other hand, the nanofibers obtained by electrospinning AEP1 and CEP3 had less uniform morphologies, along with higher standard deviations; the mean diameters of the respective fibers were found to be $470 \pm 160$ and $650 \pm 225 \mathrm{~nm}$. 


\section{WILEY-VCH}

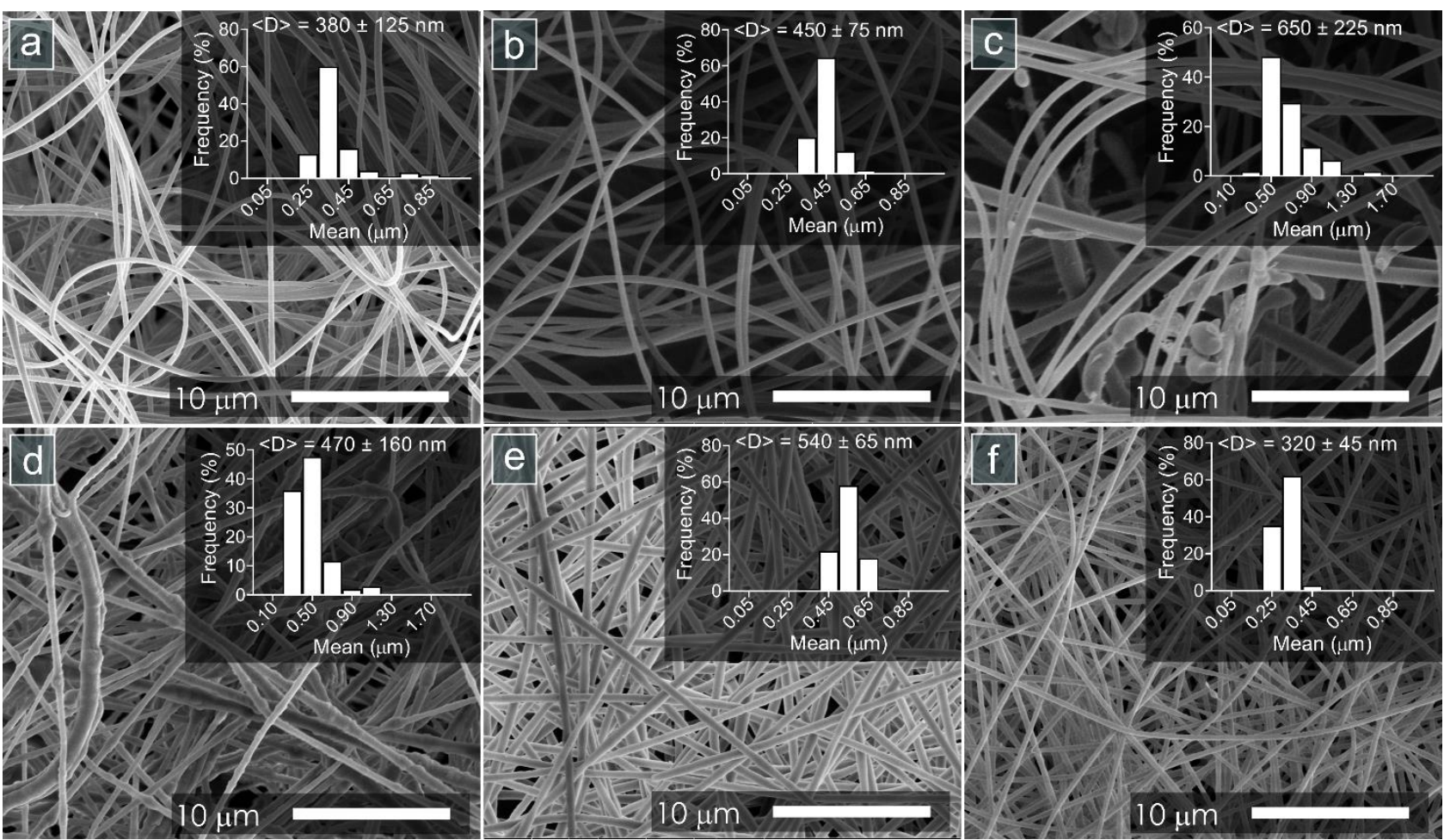

Figure 6. SEM images and fiber diameter distributions of the nanofibrous membranes made of a) CEP1; b) CEP2; c) CEP3; d) AEP1; e) AEP2; and f) AEP3.

The electrospun nanofibrous membranes underwent screening for the adsorption of a series of different dyes, namely safranin O (SO), rhodamine B (RH), methyl red (MR), methyl orange (MO), rose bengal (RB), Congo red (CR), direct red 80 (DR), and methylene blue (MB) as shown in Figure 7a. The results indicate that the anionic or cationic side groups play a role in the fine-tuning of the adsorbent properties, but these effects are generally less pronounced than those resulting from the different polymer main chains. For example, CEP1 and AEP1 both have the highest affinities towards SO and MB, which are both cationic dyes. The overall performance of the polymers on the adsorption screening can be ordered as CEP1 $>$ AEP1 $>$ CEP2 $>$ AEP2 CEP3 AEP3. The adsorptive performance of the different mats correlates well with their hydrophilicity. Generally, the more hydrophilic nanofibrous mats performed better in the adsorption experiments. This behavior was also described in previous studies where the superior performance of hydrophilic adsorbents for dye removal was attributed to the strong hydrogen bonds between the hydrophilic surface and dye molecules. $^{[42,43]}$ 


\section{WILEY-VCH}

Due to its superior performance, the nanofibrous membrane made from the CEP1 polymer was used in further studies to reveal the adsorption kinetics and mechanism and to test its recyclability. The CEP1 nanofibrous membrane (CEP1-NFM) has a high affinity toward MB and SO, resulting in a high adsorption capacity of $169.1 \mathrm{mg} \mathrm{g}^{-1}$ and $143.9 \mathrm{mg} \mathrm{g}^{-1}$, respectively, but it exhibited lower adsorption capacities for MR, MO, RH, RB, and CR, in the range of 22.2$70.8 \mathrm{mg} \mathrm{g}^{-1}$, as shown in Figure 7b. No adsorption was observed for the hexaanionic DR, suggesting a charge- and hydrophobicity-selective adsorption mechanism. Figure 7c shows the kinetic behavior of CEP1-NFM, indicating that the adsorption proceeded rapidly within the first 20 min followed by a gradual decrease in the rate until saturation was reached. MR, RB, and CR adsorption reached equilibrium after $180 \mathrm{~min}$. On the other hand, MR and SO adsorption did not stop after $3 \mathrm{~h}$, and the adsorbed amount almost doubled over the next $21 \mathrm{~h}$. The adsorption of these dyes on CEP1-NFM likely involves chemisorption, in particular ion exchange or proton transfer, because the kinetic data were best fitted with Ho's pseudo-second order model,${ }^{[44]}$ with correlation coefficients higher than 0.99 for SO and MB. Similarly, in the literature, pseudo-second order kinetic was observed in the adsorption of MB on polyacrylic acid composite materials including electrospun fibers. ${ }^{[19,45]}$ In the cases of the other three dyes, $\mathrm{MR}, \mathrm{RB}$, and $\mathrm{CR}$, the fitting of the pseudo-second order model is somewhat lower but still above 0.82 . These results suggest that adsorption of these anionic dyes is governed by different factors than in the case of the cationic SO and MB.

Figure 7d shows the adsorption behavior as a function of the adsorbent (CEP1-NFM) mass system volume ratio. The extremely high adsorption capacity for MB (962 $\mathrm{mg} \mathrm{g}^{-1}$ ) and SO (805 $\mathrm{mg} \mathrm{g}^{-1}$ ) at $0.05 \mathrm{~g} \mathrm{~L}^{-1}$ adsorbent loading was followed by a sharp decline in the adsorption capacity as the mass of the adsorbent increased, similarly to other adsorption behavior reported in the literature. ${ }^{[46]}$ The adsorption isotherm study, performed with constans adsorbent loading and various dye concentrations, revealed a Langmuir-type isotherm as shown in Figure S35. 
WILEY-VCH
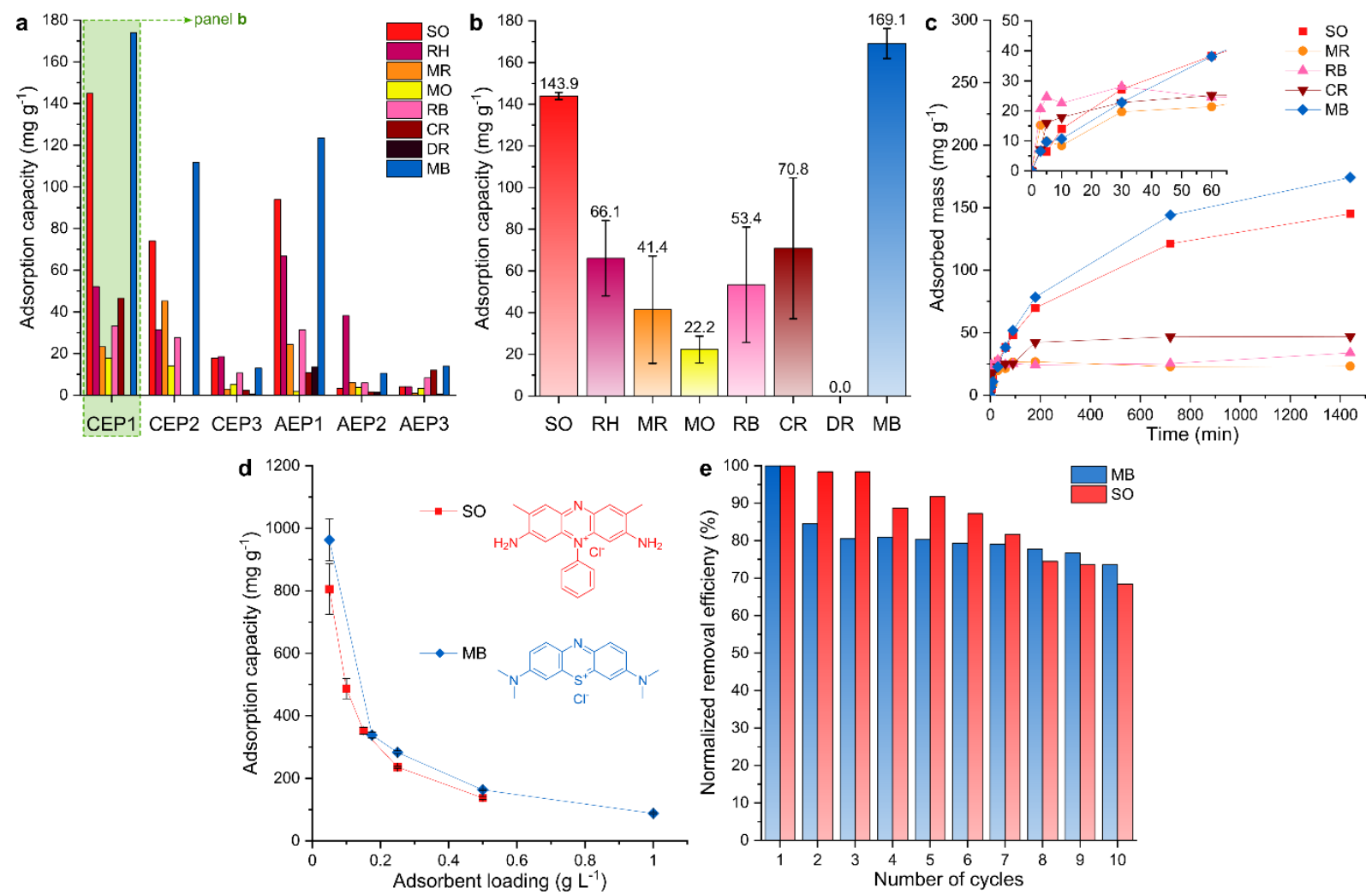

Figure 7. a) Screening of electrospun nanofibrous membranes at $0.05 \mathrm{~g} \mathrm{~L}^{-1}$ loading for the adsorption of different dyes at $100 \mathrm{mg} \mathrm{L}^{-1}$ concentration; b) equilibrium adsorption capacity of CEP1-NFM fiber $\left(0.05 \mathrm{~g} \mathrm{~L}^{-1}\right)$ for SO, RH, MR, MO, RB CR, DR and MB in water $\left(100 \mathrm{mg} \mathrm{L}^{-1}\right)$; c) kinetic isotherms of SO, MR, RB, CR and MB (100 $\left.\mathrm{mg} \mathrm{L}^{-1}\right)$ on CEP1-NFM $\left(0.05 \mathrm{~g} \mathrm{~L}^{-1}\right)$ in water; $\left.\mathrm{d}\right)$ adsorption capacity for $\mathrm{MB}$ and $\mathrm{SO}\left(100 \mathrm{mg} \mathrm{L}^{-1}\right)$ as a function of CEP1NFM loading in water; and e) a recycling study of CEP1-NFM for the adsorption of SO and MB from water.

The adsorption performance toward MB and SO of CEP1-NFM at $100 \mathrm{mg} \mathrm{L}^{-1}$ concentration and $0.5 \mathrm{~g} \mathrm{~L}^{-1}$ adsorbent loading is comparable to the performance reported in the literature in regard to adsorption capacity, equilibrium time, and reusability with a favorable advantage of operating at natural $\mathrm{pH}$ (Table S13). However, the maximum adsorption capacity of MB and SO is remarkably high at low adsorbent loading of $0.05 \mathrm{~g} \mathrm{~L}^{-1}$, suggesting the presence of lowenergy adsorption sites with high densities. Besides, we note that the kinetic behavior and adsorption mechanics of CEP1-NFM, which are best described by the pseudo-second order model and the Lagmuir isotherm, respectively, agree with other literature reports on electrospun materials, as shown in Table S13.

Regeneration and reuse experiments of any new adsorbent material are essential to assess their potential for application in practice. A survey of the literature shows that electrospun adsorbent 


\section{WILEY-VCH}

materials generally exhibit a $10-30 \%$ decrease of adsorption capacity over the first $5-10$ adsorption-regeneration cycles (Table S13). There were some electrospun fibers that lost even $62 \%$ of their capacity over just five cycles. In the case of CEP1-NFM, some decrease in the adsorption capacity can be observed in the first few cycles, similar to that in other materials, but it stabilizes thereafter. As shown in Figure 7e, the relative efficiency stabilizes after three and eight cycles for $\mathrm{MB}$ and $\mathrm{SO}$ at around $75 \%$ and $70 \%$, respectively.

Overall, the adsorption experiments demonstrated that nanofibrous membranes prepared from polyimides enhanced with ion exchange properties are promising candidates for the treatment of artificially polluted water. However, the potential of these materials does not end there. The established synthetic methodology allows the production of carboxyl-functionalized polyimides with different porosities and hydrophobicities while the proposed O-alkylation makes the introduction of strong ion exchange groups - or other functionalities - possible in a benign synthesis. These functionalized polymer materials show excellent spinnability in electrospinning techniques. Future research may explore the applicability of these materials to various other areas, such as for the removal of heavy metal ions from water, ${ }^{[15]}$ for the removal of pharmaceuticals from urine,${ }^{[4]}$ in catalysis ${ }^{[48]}$ for fuel cell applications, ${ }^{[49]}$ or as affinity membranes for protein separations. ${ }^{[17]}$ These or other yet unknown applications may be aided by potential antimicrobial properties introduced by the side groups. Gold nanoparticles and cyclodextrin decorated with alkylsulfonate ligands, as well as poly(styrenesulfonate) show broad-spectrum virostatic activity. ${ }^{[50-52]}$ The alkylsulfonic acid groups can potentially endow CEP1-CEP3 with similar properties. Quaternary ammonium-based polymers, including those with choline ester moieties similar to AEP1-AEP3 are recognized as antibacterial polymers that have been widely used for the construction of antibacterial materials. ${ }^{[53,54]}$

\section{Conclusion}

Nanofibrous electrospun polyimide membranes with strong ion exchange properties were developed as advanced adsorbent materials. Three carboxyl-functionalized polyimides were 


\section{WILEY-VCH}

prepared via one-step high-temperature polycondensation to produce porous polymers with high molecular weights in the range of $44-114 \mathrm{~kg} \mathrm{~mol}^{-1}$. Strong cation or anion exchange functionalities were introduced by a simple and benign O-alkylation step. The successful tethering of the ionic groups was confirmed by NMR, FTIR and TGA. The NMR results indicated high (0.47-0.87) and medium (0.19-0.54) alkylation degrees along with good (1.12$\left.1.23 \mathrm{~g} \mathrm{~mol}^{-1}\right)$ and moderate $\left(0.47-0.86 \mathrm{~g} \mathrm{~mol}^{-1}\right)$ total exchange capacities for the cation exchange polymers (CEPs) and anion exchange polymers (AEMs), respectively. Zeta potential analysis revealed that the surface charges of the polymers and their fibers are governed by the charge of the ion exchange side groups. All polymers exhibited good spinnability at optimized concentrations to form nanofibers with diameters in the $320-650 \mathrm{~nm}$ range.

The nanofibrous membranes were screened for the adsorption of various dyes from aqueous media. The performance varied among the different adsorptive mats with varied polymer material, side-chain functionality, and hydrophilicity. Nanofibrous membranes from CEP1 containing bicyclo[2.2.2] octenetetracarboxylic diimide units in its polymeric backbone exhibited the best adsorption capacities (up to $169.1 \mathrm{mg} \mathrm{g}^{-1}$ ) with the highest affinity towards phenazinium (MB) and phenothiazinium (SO) based dyes. CEP1-NFM also performed well in recycling experiments by demonstrating retained efficiency at around 70\% after ten adsorptiondesorption cycles. The straightforward adjustment of surface charges via O-alkylation, the ready formulation by electrospinning and the good adsorptive properties make these new ion exchange materials promising candidates in various fields, especially for the development of efficient water treatment technologies.

\section{Supporting Information}

Supporting Information is available from the Wiley Online Library or from the author.

\section{Acknowledgements}

The postdoctoral fellowships from King Abdullah University of Science and Technology (KAUST) are gratefully acknowledged (FT, MA). The research reported in this publication was supported by funding from KAUST. 


\section{WILEY-VCH}

Received: ((will be filled in by the editorial staff))

Revised: ((will be filled in by the editorial staff)) Published online: ((will be filled in by the editorial staff))

\section{References}

[1] Food and Agriculture Organization of the United Nations (FAO), AQUASTAT Main Database, https://www.fao.org/nr/water/aquastat/data/query/index.html, 2016.

[2] Organisation for Economic Co-operation and Development (OECD), OECD Environmental Outlook to 2050: The Consequences of Inaction, OECD Publishing, Paris, 2012.

[3] L. Pereira, M. Alves, in Environmental Protection Strategies for Sustainable Development (Eds.: A. Malik, E. Grohmann), Springer Netherlands, Dordrecht, 2012, pp. 111-162.

[4] N. Sajn, Environmental impact of the textile and clothing industry: What consumers need to know. PE 633.143. Briefing by the European Parliamentary Research Service, https://www.europarl.europa.eu/thinktank/en/document.html?reference=EPRS_BRI\%2 82019\%29633143, 2019.

[5] K. Hunger, in Industrial Dyes: Chemistry, Properties, Applications, (Ed.: K. Hunger), Wiley-VCH Verlag GmbH \& Co. KGaA, Weinheim, 2003, Ch.1.

[6] U. Meyer, in Microb. Degrad. Xenobiotic Recalcitrant Compd. FEMS Symp. 12 (Eds.: T. Leisinge, A.M. Cook, R. Hutter, J. Nuesch), Academic Press, London, 1981, pp. $371-385$.

[7] J. N. Chakraborty, in Fundamentals and Practices in Colouration of Textiles (Ed.: J. N. Chakraborty), Woodhead Publishing India, 2010, Ch. 32.

[8] K. Hunger, Sewekow in Industrial Dyes: Chemistry, Properties, Applications, (Ed.: K. Hunger), Wiley-VCH Verlag GmbH \& Co. KGaA, Weinheim, 2003, Ch. 8.

[9] R. Singh, A. Jain, S. Panwar, D. Gupta, S. K. Khare, Dye. Pigment. 2005, 66, 99. 


\section{WILEY-VCH}

[10] V. Katheresan, J. Kansedo, S. Y. Lau, J. Environ. Chem. Eng. 2018, 6, 4676.

[11] T. Chidambaram, Y. Oren, M. Noel, Chem. Eng. J. 2015, 262, 156.

[12] Z. Abbasi, L. Cseri, X. Zhang, B. P. Ladewig, H. Wang, in Sustainable Nanoscale Engineering (Eds.: G. Szekely, A. Livingston), Elsevier, 2020, Ch. 7.

[13] R. J. Beck, Y. Zhao, H. Fong, T. J. Menkhaus, J. Water Process Eng. 2017, 16, 240.

[14] U. A. Qureshi, Z. Khatri, F. Ahmed, M. Khatri, I.-S. Kim, ACS Sustain. Chem. Eng. 2017, 5, 4340 .

[15] S. Xie, X. Liu, B. Zhang, H. Ma, C. Ling, M. Yu, L. Li, J. Li, J. Mater. Chem. A 2015, $3,2552$.

[16] A. Celebioglu, F. Topuz, T. Uyar, ACS Appl. Polym. Mater. 2019, 1, 54.

[17] A. Celebioglu, Z. I. Yildiz, T. Uyar, Sci. Rep. 2017, 7, 7369.

[18] F. F. Ma, N. Zhang, X. Wei, J. H. Yang, Y. Wang, Z. W. Zhou, J. Mater. Chem. A 2017, 5,14430 .

[19] R. Xing, W. Wang, T. Jiao, K. Ma, Q. Zhang, W. Hong, H. Qiu, J. Zhou, L. Zhang, Q. Peng, ACS Sustain. Chem. Eng. 2017, 5, 4948.

[20] W. Chen, H. Ma, B. Xing, Int. J. Biol. Macromol. 2020, 158, 1342.

[21] M. M. Hassan, C. M. Carr, Chemosphere 2018, 209, 201.

[22] A. M. Herrera-González, A. A. Peláez-Cid, M. Caldera-Villalobos, J. Chem. Technol. Biotechnol. 2017, 92, 1488.

[23] Q. Liu, Y. Li, H. Chen, J. Lu, G. Yu, M. Möslang, Y. Zhou, J. Hazard. Mater. 2020, $382,121040$.

[24] M. A. Abdulhamid, X. Ma, X. Miao, I. Pinnau, Polymer 2017, 130, 182.

[25] Y. Rogan, R. Malpass-Evans, M. Carta, M. Lee, J. C. Jansen, P. Bernardo, G. Clarizia, E. Tocci, K. Friess, M. Lanč, N. B. McKeown, J. Mater. Chem. A 2014, 2, 4874.

[26] I. Soroko, Y. Bhole, A. G. Livingston, Green Chem. 2011, 13, 162.

[27] M. A. Abdulhamid, H. W. H. Lai, Y. Wang, Z. Jin, Y. C. Teo, X. Ma, I. Pinnau, Y. 


\section{WILEY-VCH}

Xia, Chem. Mater. 2019, 31, 1767.

[28] M. A. Abdulhamid, G. Genduso, Y. Wang, X. Ma, I. Pinnau, Ind. Eng. Chem. Res. 2020, 59, 5247.

[29] X. Ma, M. Abdulhamid, X. Miao, I. Pinnau, Macromolecules 2017, 50, 9569.

[30] H. Sanaeepur, A. Ebadi Amooghin, S. Bandehali, A. Moghadassi, T. Matsuura, B. Van der Bruggen, Prog. Polym. Sci. 2019, 91, 80.

[31] Y. Zhuang, J. G. Seong, Y. M. Lee, Prog. Polym. Sci. 2019, 92, 35.

[32] J. D. Wind, C. Staudt-Bickel, D. R. Paul, W. J. Koros, Ind. Eng. Chem. Res. 2002, 41, 6139.

[33] Y. Wang, Q. Gao, Q. You, G. Liao, H. Xia, D. Wang, React. Funct. Polym. 2016, 103, 9.

[34] J. Huang, Y. Zheng, L. Luo, Y. Feng, C. Zhang, X. Wang, X. Liu, J. Hazard. Mater. 2016, 306, 210.

[35] F. Topuz, M. A. Abdulhamid, S. P. Nunes, G. Szekely, Environ. Sci. Nano 2020, 7, 1365.

[36] M. B. Smith, J. March, in March's Adv. Org. Chem. (Eds.: M.B. Smith, J. March), John Wiley \& Sons, Inc., Hoboken, New Jersey, 2006, Ch. 10.

[37] M. N. Khan, Int. J. Chem. Kinet. 1987, 19, 143.

[38] S. Chisca, G. Falca, V. E. Musteata, C. Boi, S. P. Nunes, J. Memb. Sci. 2017, 528, 264.

[39] Z. Tian, B. Cao, P. Li, J. Memb. Sci. 2018, 560, 87.

[40] D. Ariono, Khoiruddin, Subagjo, I. G. Wenten, Mater. Res. Express 2017, 4, 24006.

[41] L. Cseri, J. Baugh, A. Alabi, A. AlHajaj, L. Zou, R. A. W. Dryfe, P. M. Budd, G. Szekely, J. Mater. Chem. A 2018, 6, 24728.

[42] J. Li, R. Wang, Z. Su, X. Ma, X. Jiang, Langmuir 2019, 35, 14920.

[43] P. Trujillo, T. González, J. L. Brito, A. Briceño, Ind. Eng. Chem. Res. 2019, 58, 14761.

[44] Y. S. Ho, G. McKay, Process Biochem. 1999, 34, 451. 


\section{WILEY-VCH}

[45] J. Yan, Y. Huang, Y. E. Miao, W. W. Tjiu, T. Liu, J. Hazard. Mater. 2015, 283, 730.

[46] M. Razali, J. F. Kim, M. Attfield, P. M. Budd, E. Drioli, Y. M. Lee, G. Szekely, Green Chem. 2015, 17, 5196.

[47] K. A. Landry, T. H. Boyer, Environ. Sci. Technol. 2017, 51, 10072.

[48] W. Shi, H. Li, R. Zhou, X. Qin, H. Zhang, Y. Su, Q. Du, Fuel 2016, 180, 759.

[49] F. Seino, Y. Konosu, M. Ashizawa, Y. Kakihana, M. Higa, H. Matsumoto, Langmuir 2018, 34, 13035.

[50] V. Cagno, P. Andreozzi, M. D’Alicarnasso, P. Jacob Silva, M. Mueller, M. Galloux, R. Le Goffic, S. T. Jones, M. Vallino, J. Hodek, J. Weber, S. Sen, E.-R. Janeček, A. Bekdemir, B. Sanavio, C. Martinelli, M. Donalisio, M.-A. Rameix Welti, J.-F. Eleouet, Y. Han, L. Kaiser, L. Vukovic, C. Tapparel, P. Král, S. Krol, D. Lembo, F. Stellacci, Nat. Mater. 2018, 17, 195.

[51] S. T. Jones, V. Cagno, M. Janeček, D. Ortiz, N. Gasilova, J. Piret, M. Gasbarri, D. A. Constant, Y. Han, L. Vuković, P. Král, L. Kaiser, S. Huang, S. Constant, K. Kirkegaard, G. Boivin, F. Stellacci, C. Tapparel, Sci. Adv. 2020, 6, eaax9318.

[52] A. Synowiec, I. Gryniuk, M. Pachota, Ł. Strzelec, O. Roman, K. Kłysik-Trzciańska, M. Zając, I. Drebot, K. Gula, A. Andruchowicz, Z. Rajfur, K. Szczubiałka, M.

Nowakowska, K. Pyrc, Antiviral Res. 2019, 170, 104563.

[53] L. G. Donaruma, Prog. Polym. Sci. 1975, 4, 1.

[54] J. Deng, X. Liu, S. Zhang, C. Cheng, C. Nie, C. Zhao, Langmuir 2015, 31, 9665. 


\section{WILEY-VCH}

Electrospun nanofibrous adsorptive membranes are developed from carboxyl-functionalized porous polyimides decorated with strong cation or anion exchange side groups. The membranes undergo morphological, chemical and thermal characterization to explore their material and structural properties. High adsorption capacities and good recyclability is observed in the treatment of phenazinium and phenothiazinium based dyes.

L. Cseri, F. Topuz, M. A. Abdulhamid, A. Alammar, P. M. Budd, G. Szekely

Electrospun adsorptive nanofibrous membranes from ion exchange polymers to snare textile dyes from wastewater

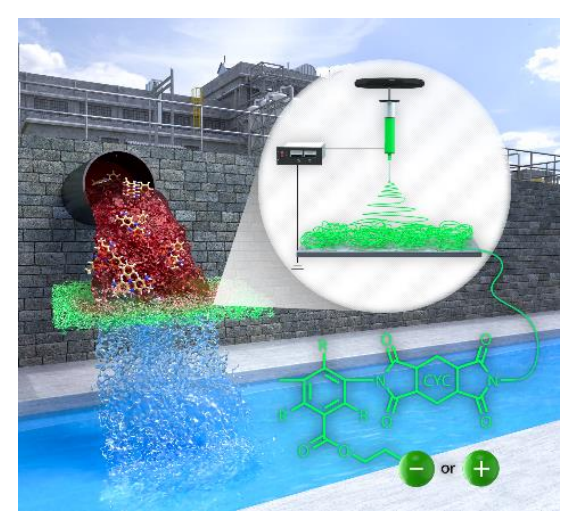

